\title{
Sinopse do gênero Weyrauchia Tippmann (Coleoptera, Cerambycidae)
}

\author{
Marcela L. Monné1,2
}

${ }^{1}$ Museu de Zoologia, Universidade de São Paulo. Caixa Postal 42494, 04218-970 São Paulo-SP, Brasil.

${ }^{2}$ Bolsista da FAPESP.

\begin{abstract}
Synopsis of the genus Weyrauchia Tippmann (Coleoptera, Cerambycidae). The genus Weyrauchia Tippmann, 1953 is redefined and W. aeruginosa sp. nov. is described from Brasil (Bahia). All the species are illustrated and keyed.

Keywords. Cerambycinae; synopsis; taxonomy; Trachyderini; Weyrauchia.

Resumo. Apresenta-se a redescrição do gênero Weyrauchia Tippmann, 1953 e a descrição de W. aeruginosa sp. nov. procedente da Bahia, Brasil. As espécies são ilustradas e chave para identificação é fornecida.

Palavras-chave. Cerambycinae; sinopse; taxonomia; Trachyderini; Weyrauchia.
\end{abstract}

O gênero Weyrauchia foi proposto por Tippmann (1953) para Weyrauchia viridimicans, de Cajamarca (Peru). O mesmo autor, em 1960, descreveu W. nobilis também de Cajamarca (Peru). Apresenta-se a redescrição do gênero, a descrição de Weyrauchia aeruginosa sp. nov., proveniente da Bahia (Brasil), e chave de identificação para as espécies. O material estudado pertence ao Museu Nacional, Universidade Federal do Rio de Janeiro, Rio de Janeiro (MNRJ).

Weyrauchia Tippmann, 1953

Weyrauchia Tippmann, 1953: 226; Monné, 1994: 79; Monné \& Giesbert, 1995: 115.

Espécie-tipo: Weyrauchia viridimicans Tippmann, 1953 (designação original).

Fronte curta, vertical. Genas subtriangulares, tão longas quanto a metade do diâmetro do lobo ocular inferior. Olhos pouco desenvolvidos, pouco estreitados entre os lobos; lobos superiores estreitos e os inferiores com aspecto triangular. Tubérculos anteníferos moderadamente distantes entre si, pouco projetados e com ápices arredondados. Mandíbulas curtas, triangulares, margem externa arredondada e ápices aguçados. Antenas com 11 antenômeros. Sistema porífero presente na margem lateral externa nos III-XI e dividido por carena mediana. Escapo cilíndrico e gradualmente expandido para o ápice. Antenômero III apenas mais longo que o escapo; IV cerca de um terço mais curto que o III; XI apendiculado e cerca de 1,5 vezes o comprimento do $X$.

Protórax quase tão largo quanto longo; arredondado aos lados, com ou sem projeções espiniformes. Pronoto densamente pontuado. Processo prosternal cerca de um terço do diâmetro de uma procoxa e tuberculado no ápice. Cavidades cotilóides anteriores arredondadas aos lados e abertas atrás. Mesosterno deprimido no meio. Processo mesosternal tão largo quanto o diâmetro de uma mesocoxa, ligeiramente convexo e com projeções laterais para encaixe nas mesocoxas. Cavidades cotilóides médias fechadas lateralmente. Escutelo curto, transverso e com a margem apical arredondada. Élitros cerca de duas a três vezes o comprimento do protórax, pouco mais largos que o protórax na base e com os lados ligeiramente estreitados para os ápices. Superfície densamente pontuada. Extremidades elitrais arredondadas. Úmeros arredondados, não-projetados. Pernas posteriores cerca de 1,5 vezes o comprimento das anteriores. Pro- e mesocoxas arredondadas e não-salientes. Fêmures lineares. Meso- e metafêmures, no ápice interno, com aba aguçada. Tíbias cilíndricas, deprimidas e tão longas quanto os fêmures. Tarsos curtos; metatarsômero I mais curto que os II-III reunidos; escovas tarsais compactas. Urosternito I um terço mais longo que o seguinte. Urosternito $\mathrm{V}$ transverso e truncado na margem apical.

Discussão. Tippmann (1953) considerou Weyrauchia semelhante a Tragidion Audinet-Serville, 1834. ZaJCiw (1961), entretanto, considerou o gênero próximo de Micropelta Zajciw, 1961 (Fig. 4) e Deltaspis Audinet-Serville, 1834, principalmente por apresentarem colorido metálico. A opinião de ZAJCIW (1961) parece mais apropriada já que estes três gêneros apresentam, ainda, os élitros glabros ou subglabros, sem costas e com pontuação densa. A maioria das espécies de Tragidion não apresenta colorido metálico, os élitros são pilosos, com costas evidentes e pontuação pouco aparente.

Weyrauchia difere de Deltapis e Micropelta por apresentar as cavidades cotilóides médias fechadas lateralmente. Difere, em particular, de Deltaspis por apresentar o antenômero IV cerca de um terço mais curto que o III, protórax não alargado aos lados e escutelo transverso. Em Deltaspis, os antenômeros III-IV são subiguais em comprimento, o protórax é alargado aos lados e o escutelo é triangular. Weyrauchia difere, ainda, de Micropelta pelos tubérculos anteníferos com ápices arredondados, pronoto densamente pontuado e processo mesosternal ligeiramente convexo. Em Micropelta (Fig. 4), os ápices dos tubérculos anteníferos são bem aguçados, o pronoto apresenta estrias transversais e o processo mesosternal é tuberculado. 

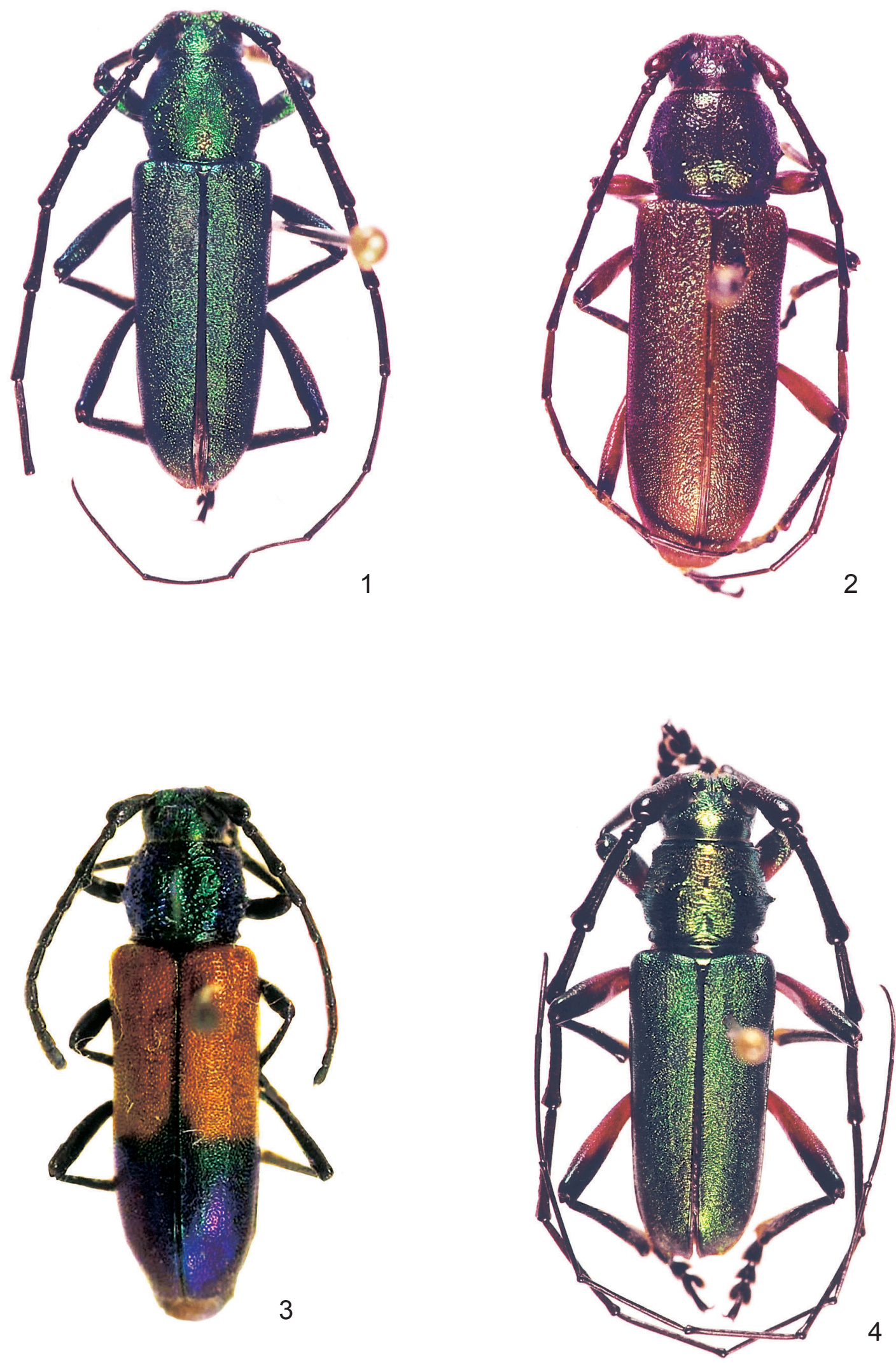

Figs. 1-4. 1, Weyrauchia aeruginosa sp. nov., holótipo macho, comprimento $15,5 \mathrm{~mm} ; \mathbf{2}$, W. viridimicans Tippmann, 1953, fêmea, Peru, Jaen, comprimento 15,6 mm; 3,W. nobilis Tippmann, 1960, holótipo fêmea, comprimento 14,5 mm; 4, Micropelta rugosicollis Zajciw, 1961, Brasil, Rondônia (Ariquemes), comprimento $17,8 \mathrm{~mm}$. 
Chave para as espécies de Weyrauchia

1. Lados do protórax inermes; cabeça, tórax e élitros com colorido verde-metálico (Fig. 1). BRASIL (Bahia) .... W. aeruginosa $\mathbf{s p . ~ n o v . ~}$

Lados do protórax com projeção espiniforme; corpo com outro padrão de colorido . .2

2(1). Tegumento castanho-avermelhado; cabeça, protórax e élitros com reflexo verde-metálico; pronoto com pontos finos (Fig. 2). PERU

W. viridimicans Tippmann, 1953

Cabeça e protórax com colorido verde-metálico; élitros bicolores, na metade basal alaranjados e na apical com reflexo verde a azul-metálico; pronoto com pontos grossos (Fig. 3). PERU

W. nobilis Tippmann, 1960

\section{Weyrauchia aeruginosa sp. nov.}

(Fig. 1)

Macho. Colorido geral verde-metálico; élitros com colorido verde a azul-metálico; antenas (exceto escapo), tíbias e tarsos, pretos; fêmures com tegumento preto e reflexo azul-metálico; abdome castanho.

Cabeça glabra e densamente rugoso-pontuada. Fronte com estrias transversais. Genas densamente pontuadas. Lobos oculares superiores com oito fileiras de omatídios e a distância entre os lobos cerca de quatro vezes a largura de um lobo. Antenas ultrapassam os ápices elitrais no antenômero VIII. Sistema porífero em toda margem lateral dos antenômeros IVXI e no terço apical do III. Escapo com pontos grossos e densos; antenômeros III-V sulcados no dorso; V ligeiramente mais longo que o IV; VI-X subiguais em comprimento.

Lados do protórax inermes. Pronoto com pontos finos e densos e com três faixas longitudinais com estrias transversais, a mediana apenas na metade posterior e duas, a cada lado da mediana, da margem anterior à posterior. Esternos torácicos com pêlos curtos, esparsos e esbranquiçados. Prosterno e mesosterno com pontuação finíssima e densa. Metasterno com pontos grossos e moderadamente densos. Élitros com pontuação pouco maior que a do pronoto. Fêmures e tíbias com pontos grossos e densos. Abdome com pontos finos, rasos e densos e pubescência esbranquiçada.

Dimensões, em mm, macho. Comprimento total, 15,5; comprimento do protórax, 3,8; maior largura do protórax, 4,2; comprimento do élitro, 9,6; largura umeral, 4,4.

Material-tipo. Holótipo macho. BRASIL. Bahia: Cândido Sales, XI.1972, Seabra \& Roppa col. (MNRJ).

Discussão. Weyrauchia aeruginosa sp.nov. assemelha-se à $W$. viridimicans pelo colorido uniforme dos élitros, pelo pronoto com pontos finos e difere pelos caracteres descritos na chave.

Agradecimentos. Ao Dr. Miguel A. Monné (MNRJ) pelo empréstimo do material. Ao Dr. Steve Lingafelter (USNM) pela foto do holótipo de Weyrauchia nobilis. À FAPESP pela concessão da bolsa de estudo (Proc. 03/00511-3).

\section{REFERÊNCIAS}

Monné, M. A. 1994. Catalogue of the Cerambycidae (Coleoptera) of the Western Hemisphere. Part XI. Subfamily Cerambycinae: Tribes Torneutini, Trachyderini and Basipterini. São Paulo, Sociedade Brasileira de Entomologia, 157 p.

Monné, M. A. \& E. F. Giesbert. 1995. Checklist of the Cerambycidae and Disteniidae (Coleoptera) of the Western Hemisphere. Burbank, Wolfsgarden Books, xiv +419 p.

Tippmann, F. F. 1953. Studien über neotropische Longicornier I (Coleoptera: Cerambycidae). Dusenia 4: 181-228.

Tippmann, F. F. 1960. Studien über neotropische Longicornier III (Coleoptera, Cerambycidae). Koleopterologische Rundschau 37-38: 82-217.

ZaJciw, D. 1961. Novos Stenaspini (Col., Cerambycidae, Cerambycinae) neotrópicos. Anais da Academia Brasileira de Ciências 33(34): 399-407. 